\title{
Misrepresentations of Lone Shooters: The Disparate Treatment of Muslim, African American, Hispanic, Asian, and White Perpetrators in the US News Media
}

\author{
Cynthia M. Frisby \\ Department of Strategic Communication, School of Journalism, University of Missouri, Columbia, USA \\ Email: FrisbyC@missouri.edu
}

How to cite this paper: Frisby, C. M. (2017). Misrepresentations of Lone Shooters: The Disparate Treatment of Muslim, African American, Hispanic, Asian, and White Perpetrators in the US News Media. Advances in Journalism and Communication, 5, 162-181.

https://doi.org/10.4236/ajc.2017.52010

Received: March 29, 2017

Accepted: June 27, 2017

Published: June 30, 2017

Copyright $\odot 2017$ by author and Scientific Research Publishing Inc. This work is licensed under the Creative Commons Attribution International License (CC BY 4.0).

http://creativecommons.org/licenses/by/4.0/

\begin{abstract}
The purpose of the present study is to determine how news stories about mass shootings are framed when reporting on a lone shooter. Data obtained revealed specific biases in news stories about mass shootings and perpetrators of color. National print media included in the study were USA Today, the Washington Post, The New York Times, the St. Louis Post-Dispatch, and the Los Angeles Times. Data shows that of the $\mathrm{N}=170$ stories, $75 \%$ of the stories involving a white shooter included the word or references to hero while shootings that involved lone shooters of color using the hero was found in $25 \%$ of the stories $(P<.001)$. Results from this research are discussed in terms of their implications and significance for future research.
\end{abstract}

\section{Keywords}

Lone Shooters, Tragic and Violent News, Portrayals of Minorities in News Stories about Crime

\section{Introduction}

Dylann Roof, Adam Lanza, James Holmes, Jared Loughner, Eric Harris and Dylan Klebold-These are the names of the men who are known to have committed mass shootings, killing and/or injuring innocent people. These are the names of men who have been associated with mass shootings, killing and/or injuring innocent people in a public place. The one commonality behind these six names is the fact that they are young, white, and male. Black men of color do not typically represent the majority of mass shooters or mass murderers. The present study investigates simultaneous portrayals of multiple minority groups in news 
stories about mass shootings and tragic events. Previous research on this topic focuses on White/Black distinctions and other studies focus on media portrayals of Muslim and Hispanic shooters/bombers/terrorists, but few studies compare all of the media portrayals in one study. This exploratory study-focusing mostly on framing-was designed to provide a starting point that helps to encourage larger, more developed research on how lone shooters are portrayed in media and how frames may be used to encourage, maintain, and/or create stereotypes.

Research tells us that, for example, the frequency with which the media represent alleged perpetrators has significant impact on the development of stereotypes and attitudes toward criminals and victims. For example, it is possible that the overrepresentation of certain groups (e.g., males, people of color, etc.) as perpetrators in news stories may encourage the development of racial and/or gender stereotypes or better yet encourage public anger towards such groups (e.g., Barlow, Barlow, \& Chiricos 1990; Dixon, Azocar, \& Casas 2003; Dixon \& Linz, 2000a, 2000b; Russell, 1998). In light of their potential influence, a number of researchers have directed their investigations to focus on how racial and ethnic groups are portrayed in crime news stories. Recent studies reveal that most school shooters are white males, with 97 percent being male and 79 percent being white. Over the last decade, 90 percent of all mass shootings were the result of white, often upper-middle class, male perpetrators. Yet, despite the proliferation of studies, findings about the frequency of words used to describe alleged perpetrators in media representations of crime vis-á-vis race-ethnic groups are not as readily accessible.

Research provides some evidence that racial minorities (especially, African Americans) are overrepresented in news stories focused on perpetrators of violent crime (e.g., Frisby, 2015; Dixon \& Linz, 2000a, 2000b), however, what is still left to understand is how alleged shooters involved in mass tragedies are framed in national news coverage of tragic events. This study seeks to compare media portrayals of White, Black, Hispanic, Muslim, Asian, and Pacific Islanders in news stories about tragic violent events.

\section{Background}

Media tend to depict a large proportion of violent offenders as racial and ethnic minorities, even though a much smaller percentage are involved in the criminal justice system (see Reiner, Livingstone, \& Allen, 2003). Minorities, therefore, are overrepresented as offenders in the news (Barlow, 1998; Gilliam \& Iyengar, 2000). Research by Entman (1990, 1992, 1994a, 1994b) finds that in television news stories, Black (compared to White) suspects are less likely to be identified by name, are not as well dressed, and are more likely to be shown physically restrained. Yet, while Blacks are overrepresented as offenders, they are typically underrepresented as victims in the news (Weiss \& Chermak, 1998; Pritchard \& Hughes, 1997). One study found that newsworthiness increases when the victim of a crime is White and another study found that homicides with White victims resulted in more and longer articles than homicides with Black victims (Reiner, 
Livingstone, \& Allen, 2003). Interestingly enough, media as well as official crime statistics are in agreement on one aspect of criminal offenders: they are more often males (see Reiner, Livingstone, \& Allen 2003; Sacco, 1995: p. 143).

Some of the worst recent mass shooters in the United States-the Colorado theater gunman, James Holmes, with his orange-dyed hair; the Virginia Tech shooter; Adam Lanza the gunman involved in the tragic school shooting at Sandy Hook elementary school in Newtown, Connecticut, in December 2012; Jared Loughner the gunman who shot US Congresswoman Gabrielle Giffords and 6 other people at a political rally in Tucson, Arizona; and, U.S. Maj. NidalHasan, an Army psychiatrist, who was convicted in 2013 of killing 13 people (see Figure 1).

According to the data presented in Figure 1, "between 1982 and 2016, 48 out of 83 mass shootings were initiated by White shooters" (Statista, 2017). Thus, it can be hypothesized that a great majority of mass shootings in the United States over the last 34 years have been carried out by men. Statista (2017) conducted research and analyzed the factors that most Americans considered to be to blame for these mass shootings. Data obtained in their study showed that 48 percent of the participants in their survey felt that the cause of mass shootings is the direct result of the inability of the mental health system to recognize those who pose a danger to others. In the wake of multiple mass shootings, it was determined that research must look beyond the issue of shooter identification and

\section{Number of mass shootings in the United States between 1982 and 2016, by shooter's race and ethnicity}

60

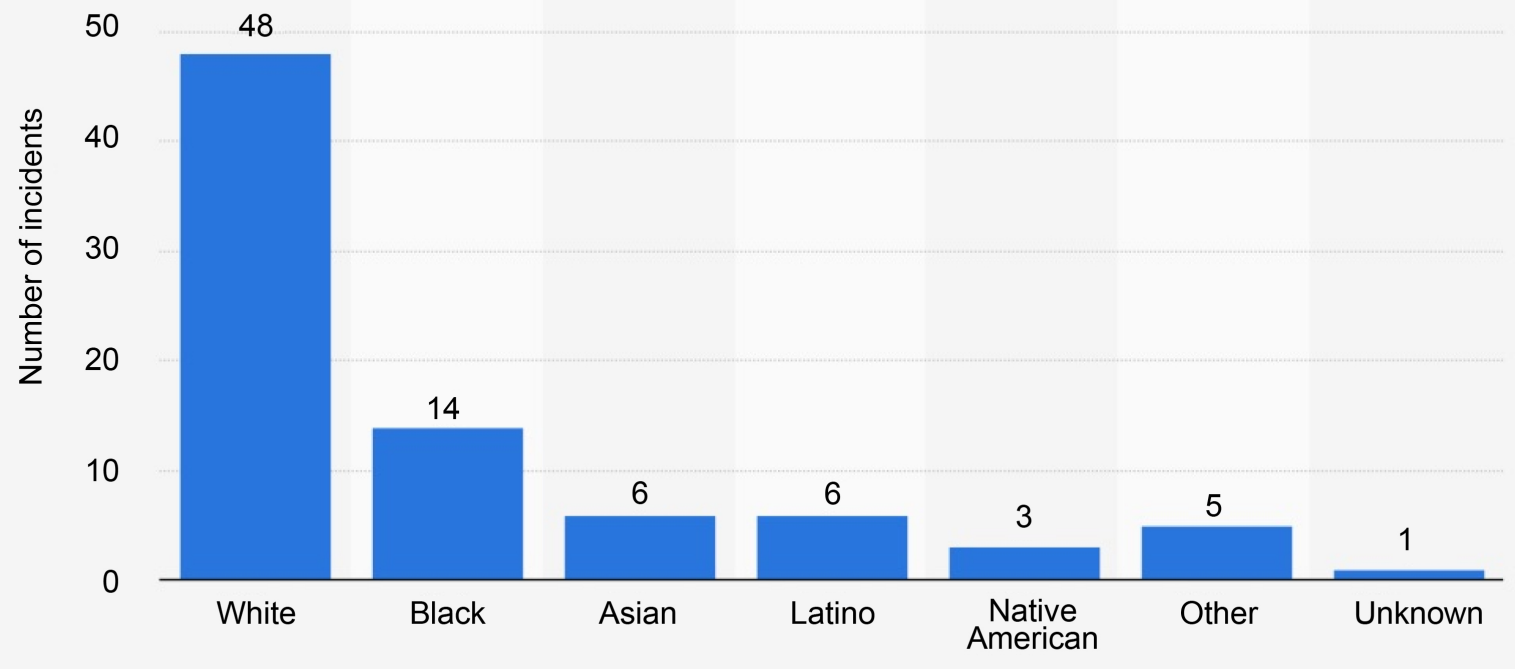

Source:

Mother Jones

(C) Statista 2016

Additional Information:

United States; 1982 to 2016

Figure 1. The number of mass shootings by race and ethnicity of the shooter(s). 
the influences by focusing on the role the media play in shaping our perceptions of these influences. In other words, to what extent will research find news stories that involve shooters and mental health influences?

Research tells us that African Americans committed close to $16 \%$ of the mass shootings, as of 2014 while Asians were responsible for around 9\% and those identified as either Latino, Muslim, and Native American rounded out the study (Statista, 2017). Data presented in Figure 1 shows that the number of mass shootings in the United States between 1982 and 2016, by race and ethnicity of the shooter, were initiated by White shooters.

\subsection{Portrayals of People of Color in Tragic News}

Chiricos and Eschholz (2002) found that Blacks and Hispanics are disproportionately portrayed as criminal suspects in news stories. More specifically, Blacks were nearly two and a half times and Hispanics over five and a half times more likely to be presented in roles as criminal suspects than Whites. In terms of the relative frequency of the portrayal of race and ethnic groups as criminal suspects versus as victims or in conventional roles (e.g., as police officers, reporters, or other positive role model), Chiricos and Eschholz (2002) further found evidence that supported the fact that people of color are four times more likely to be portrayed in news stories as suspects than as victims of crime, while Whites are not. Prior research has not examined differences in media coverage of perpetuators of mass shootings.

Differences can also be found in news media in terms of portrayals of blacks as victims. We find that media rely on different practices when covering crimes involving African Americans, Hispanics, Asians, or Muslims. As suspects, they are quickly characterized as terrorists and thugs motivated purely by evil intent (Butler, 2015). While white suspects are often described as "lone wolves"violent acts created by one angry white person. Black victims are often vilified and evidence for that can also be found in news stories. The lives of Black victims in news stories often provide subtle cues that the justification for the murder or shooting are behaviors that they are responsible for. For example, because Trayvon Martin was wearing a hoodie, that behavior was framed in stories as being just as responsible for his death as his shooter. News stories on the Michael Brown shooting often times framed the event around the thought that Brown stole cigars from the convenience store. In other words, in terms of Black victims, media often times frame the event that somehow offers a justification for their deaths.

\subsection{Mass Shooters and Mental Health}

Mental health advocates have frequently expressed their concern that the news media's focus on mass shooters and mental illness could lead consumers to view mental illness as a cause of tragic shootings (Appelbaum \& Swanson, 2010). Social psychology research suggests that news stories that describe mass shooting events by race or mental illness could lead the public to wrongly either as a pri- 
mary causal factor in tragic shootings. For instance, McGinty, Webster, Jarlenski, and Barry (2014) surveyed 1797 adults in the U.S., and randomly assigned respondents to four groups: a control group which did not read any news story, a group which read a news story describing a mass shooting by a person with a serious mental illness, a group which read a news story describing the same mass shooting that also described a proposal for gun restrictions for persons with serious mental illness, and a group which read a story describing the same mass shooting that also described a proposal to ban large-capacity magazines. Data obtained in the experiment showed that those news stories that framed a shooter with mental illness increased negative attitudes toward persons with serious mental illness.

Researchers also found that fifty-four percent of respondents who read a news story of a mass shooting thought persons with serious mental illness were likely to be dangerous, compared to $40 \%$ in the control group (Jarlenski \& Barry, 2014). Based on the fact that the number of mass shootings in the U.S. have been White men, we hypothesize that mental illness will be found to occur more frequently with White shooters than shooters of color.

\subsection{Research on Shooters of Color and News Coverage}

Studies that center on the representation of minority groups in media and news coverage seem to focus on the consequences of exposure to crime stories, racial conflicts, and development or maintenance of stereotypes and bias toward members of minority groups. To address the possibility that media content may enhance stereotyping, it was determined that research attention must be given to the words and adjectives found in print media used to describe alleged perpetrators, particularly in terms of race. We focused on adjectives used in the news stories because the adjectives/nouns found in the story might be used to suggest how shooters are presented to the audience (called "the frame").

Focusing on the words contained in news stories about mass shootings, researchers can begin to unpack and understand how the news media frame such tragic events and at the same time, we will seek to determine if different adjectives and nouns are used for different types of shooters (i.e., Caucasian, African American, Latino, Asian, Native American, Muslim, Pacific Islander). Using framing as a theoretical framework to guide the study, we seek to answer three basic research questions: First, what type of racial information about a crime involving a mass shooter is provided to consumers in newspapers? In other words, to what extent do crime news stories focus attention on uncharacteristic offenders? Second, do differences in the types of facts used in a crime story exist among various racial groups? Thus, will newspapers report in different frequencies objective and subjective facts for shooters belong to different ethnic groups? And third, how do portrayals of offenders' mental health vary in newspaper coverage?

\subsection{Theoretical Background}

In this study, we examine a subset of news stories that focus specifically on the 
mental health of shooters to ascertain how atypical White offenders and offenders of color are represented in the news. How is the phenomenon of mass shootings constructed in the media discourse? One of the best ways to answer this question is to examine the content of the stories themselves. To answer the question we will analyze the various ways news mediaframe the perpetrators.

Research on framing effects is concerned with differences in the way information is delivered and exploring how the differences affect attitudes, emotions, and decisions of media users (Iyengar, 1991; Pan \& Kosicki, 1993; de Vreese, 2005). According to Druckman (2001) framing studies can be separated into two distinct types depending on the kind of framing effect studied (Druckman, 2001b). The first type of frames is known as "valence." Valence as a framing effect investigates the use of different, but comparable words, might be used to draw attention to aspects of a story. In other words, using this theory, it is hoped that we can determine if media highlight positive or negative aspects of mass shooters by framing the event in one of two ways (e.g. 5\% undocumented citizens versus 95\% Latinos as American citizens). The simple use of words, research shows, can prompt different responses (e.g. Kahneman \& Tversky, 1984). This type of framing research is referred to as "wording effects." The present study hopes to build on this line of research by exploring the way that news stories about mass shooters use words to bring attention to the news story.

The second type of frame, according to Nelson, Lechler, Schuck and Vreese (2012), is equivalent to "real" journalistic news coverage' (Nelson, Lecheler, Schuck, \& Vreese, 2012: p. 3) and is concerned with the effects of media and messages on individuals. This type of framing allows researchers to present alternative perspectives on the topic and often times will stress different aspects of complex issues. This type of frame analysis is clearly a media effects model. Since the current study is exploratory and focused on identifying the type of frames found in stories about mass shootings, we rely on framing theory that investigates the use of different words.

Framing is a relevant theory and provides an important framework to study the issue of mass shootings and how those events are highlighted in print media in order for readers to make sense of the tragedies. The frames (and/or adjectives) used in the news stories can regulate the audience's perception and also their acceptance of the particular subtle meaning implied in the story. We know that media play an important role in the development on self-perceptions, and is a powerful tool. Journalists select the news stories influenced by many factors such as newsworthiness, shock value, news values, editorial policies, and interaction with the readers. These factors build frames in stories. With the interaction between the media and the preconceptions of the people, framing plays an important role in how the particular issue is been presented before the people and how they perceive it.

\section{Method}

A content analysis was designed and conducted for this study to test the statis- 
tical significance of relationships between the race of lone shooters and words used to describe the shooters. Content analysis is a quantitative research method that involves exploring the images and representation of subordinate groups in a representative sampling of media (Berger, 1991). Krippendorff (2004a), defines content analysis in relation to this study as: “... the analysis of the manifest and latent content of a body of communicated material (as a news stories) through classification, tabulation, and evaluation of its keys symbols and themes in orders to ascertain its meaning and probable effect." Similarly, Mittell (2004) defines content analysis as the setting of specific boundaries to measure within a selected group of programs and count the appearance of characters that fit into the identified categories. Mittell also suggests that content analysis is best for answering questions where the coding groups are clear-cut.

\subsection{Selection of National Newspapers}

We selected USA Today, the Washington Post, The New York Times, the St. Louis Post-Dispatch, and the Los Angeles Times because they were cited as the most highly circulated newspapers. After crime stories were gathered from newspaper archives, we read the stories line by line and, using SPSS, coded them "on what was portrayed, reported, suggested or implied in the context" (Grabe, 1999). We coded a variety of variables: Date of news story, List of crimes that occurred (e.g. murder, sexual assault, robbery), multiple offenders $(0=$ no, $1=$ yes, $99=$ missing $)$, multiple victims $(0=$ no, $1=$ yes, $99=$ missing $)$, Race of of fender reported $(1=$ White, $2=$ Black, $3=$ Hispanic, $4=$ Asian, $5=$ Muslim, $6=$ Pacific Islander, $99=$ missing), Was the story a lead story $(0=$ no, $1=$ yes $)$.

We also coded the headline to provide insight into the focus of the news story. As such, the coding of the headline into categories was based upon the main theme of the headline. Headlines were coded into one of three themes-shooter, $\operatorname{victim}(s)$, or event-based on the focus of the headline. Coding of the headlines was discrete, meaning that they only could be categorized into one of these themes.

\subsection{Criteria for Selection of Crime Stories}

In order to be in the sample, a crime story had to cover mass murders by a lone shooter. Over the study period 2008-2016, we collected and coded 170 crime stories resulting in our sample. It is important to note that the unit of analysis for this study is the report of a crime story, not the crime itself.

The term "mass shooting" for purposes of this study was understood to be a shooting that happens in a public place and claims four or more lives and attracts widespread media coverage (personal communication, 2017). The random nature of indiscriminate shots and gunfire being unleashed without warning was also considered criteria for selection. It was the perception that this tragic event could have happened anywhere. For example, within the last three years, one lone gunman walked into a church have massacred worshipers there, another lone shooter unleashed gunfire at a night club, and several years ago, another 
lone shooter shot and killed young children at an elementary school. Many of these events have been framed in national media as the "deadliest mass shootings in modern American history within the last decade".

\subsection{Unit of Analysis}

To evaluate news media coverage of mass shootings, we analyzed a random sample of news stories focused on lone shooters and gun violence from 2008 to 2016. We began our study period in 2008 to capture coverage of the shootings in Colorado, Fort Hood, and elsewhere, during the mid-2000s. News sources included two of the highest-circulation national newspapers in the United States in 2014 (USA Today and Washington Post) and three of the highest circulation newspapers in regional areas of dominant influence, including the Northeast (New York Times), and Midwest (St. Louis Post-Dispatch) and the West (Los Angeles Times). The Audit Bureau of Circulation was used to identify newspaper circulation rates as of 2016.

After the elimination of duplicates, reprints, and stories with high similarity, the search resulted in a total of 170 news stories. We specifically sought news media with high circulation rates across the country so that we might be able to assess news coverage that reached a large subset of the American people.

To select news stories and stories that focused solely on violent/mass shootings, we relied on our media librarians to assist in locating all relevant articles published during the time period. We used ProQuest online archives to collect news media stories. Next, in order to obtain a sample of news stories, the following search terms were used: "mental illness" or "mental disorder" or "mental health disorder" or "mental disorder" or "mental illness" "hero," "terrorist," "thug," "criminal," "hoodlum," "gangster," "bomber," "assassin,” "extremist," AND "mass" or "tragic shooting" or "mass violence" or "tragedy" or "victims shot" or "mass violence" or "innocent victims," or "tragic killings." We searched the database for complete news articles, including headlines.

We then reviewed each story and excluded those that were not focused on lone shooters, race, or tragedy. News stories shorter than 100 words or classified as corrections, book reviews, letters to the editor, business or stock, obituaries, duplicate wire stories, story previews, or calendar reports were also excluded. The final sample consisted of 170 news stories.

Framing analysis is an especially effective method particularly when analyzing a single or small number of news stories in depth (Lewis \& Reese, 2009). The large number of news stories collected from multiple sources made it necessary to verify that the themes and words identified during the analysis were, in fact, common among all stories and that they did in fact appear frequently in headlines to warrant attention. Therefore, data analysis focused on how frequently the coded categories/themes appeared in the headlines of news stories about mass shootings.

What components in a news story constituted a frame? Entman (1993) suggested that frames in the news can be examined by "the presence or absence of 
certain keywords, stock phrases, stereotyped images, sources of information and sentences that provide thematically reinforcing clusters of facts or judgments. A list of frames to analyzed are: Headlines, Sub headlines, Photos, Photo captions, Leads, Source selection, Quotes selection, Pull quotes, Logos, Statistics and Charts. In sum scholars often agree that frames are specific textual and visual elements for framing devices (de Vreese, 2005). Framing research supports the idea that headlines are frequently used and can be used as tools for research on framing (Entman, 1993). Furthermore, headlines that use stereotypical language, according to research, is the most effective indicator on stereotypical frames because the very purpose of a headline is to tell the reader what the story is about (de Vreese, 2005).

\subsection{Codebook and Coding Categories}

Newspaper: Indicate which newspaper the article was printed in: 1) USA Today, 2) Washington Post, 3) New York Times, 4) St. Louis Post-Dispatch, and 5) Los Angeles Times,

Article ID: Each newspaper had its own identifier-each article was numbered in numerical order with the appropriate identifier listed first (e.g., USA1, USA2, USA3, WP1, WP2, WP3, etc.)

Coder ID: Indicate the name of the individual who coded the news report according to their initials (e.g., IC or TP)

Date: Enter the date of the newspaper as mm/dd/yy (e.g., 08/22/06)

Headline: Enter the headline exactly as it appears. If the headline consists of a lead headline, followed by a sub-headline, enter them both, separated with a colon. (e.g., One last chance to live: A change of heart by Page would set appeal in motion) Rapid City Journal, 08/21/06.

Ethnicity of Offender/Perpetrator: Caucasian, African American, Hispanic, Asian, Native American, Muslim, Pacific Islander, Other.

Type of Fact: As previously stated, according to Singletary and Lipsky (1977), the term "objective" fact should be coded as an indisputable and unbiased aspect of the story. (i.e. sex of offender, and age of offender.) Subjective facts refer to aspects of a news report that are unnecessary for a complete understanding of what happened and that can often introduce bias into the report.

Descriptive Language/Frame/Theme Used: ${ }^{*}$ The following categories and termes were developed based on scholarly works as well as news stories and blogs found on online news sites that specifically mentioned the association between the word used and the ethnicity or attribute of the shooter (see The Washington Post, Huffington Post, etc.). Examples of the headlines found will be discussed later in the results section of the paper.

Hero: To qualify as hero, the news story must focus on a degree of personal risk. For example, an individual that returns to a house fire in order to help others get out has would be coded as a heroic action. Throwing oneself in the way of a gunman in order to "take the bullet" would be another example of descriptive language fitting this category (Strate, 1985). American media, according to re- 
search, tend to portray White lone shooters often as heroes who use violence as a justified means of resolving conflict and prevailing over others (Dietz, 1998). Based on research in this area, we expect to find that news coverage about shootings will justify the act by relying on words that portray the use of violence as a heroic act used to seek revenge, often without consequences.

Terrorist/terrorism: The shooter allegedly uses victims and targets for political and symbolic purposes (Lewis, 2005). Attacks are designed to create an atmosphere of fear or a sense of threat (Lewis, 2005). Saleem, Prot, Anderson, \& Lemieux (2015) found evidence that supports the idea that news stories often portray Muslims as terrorists and the effects of this portrayal is a positive association with perceptions that Muslims are aggressive, violent, and should have restrictions for entering America.

Thug/Criminal: This is the media practice of depicting Blacks as criminals. News outlets regularly use mugshots to depict and highlight criminal histories, reinforcing dangerous and racist stereotypes about Blacks. Depictions of a Blackshooter as a criminal or "thug" with an arrest record, becomes easier to hold firm to the misperception that all Blacks, particularly men thugs and criminals (Smiley \& Fakunle, 2016). Many of the depictions of Black males are as pimps, thugs, hustlers, and law-breaking individuals who are not to be trusted, and are not worthy of equal treatment (Howard, Flennaugh, \& Terry, 2012; Milner, George, \& Allison, 2016). According to Howard, Flennaugh and Terry (2012) Black men, according to depictions, are prone to violence, and constantly involved in gangs and drugs. Therefore, it is hypothesized that these depictions will be found in news stories about tragic, violent crime.

Mental Illness: When media refer to mentally ill individuals as incompetent, dangerous, slovenly, violent, unable to control rage, have disheveled hair, are childish and silly, and are unable to recover from their "illness." Common news account of mental illness, for instance, involve a sensationalized and violent crime in which an innocent person/s is killed by a mental health individual (Fawcett, 2015). Prior research in this area continues to show that mass media accounts of violence often see shooters as suffering from some kind of mental illness (McCauley, Moskalenko, \& Van Son, 2013). Studies have found that lone shooters are typically portrayed as insane only because they killed or injured others for motives that appear to be incomprehensible to a majority of rational Americans (Wing, 2014). It is plausible that news media report tragic shootings and other crimes in such a way that the reader understands that the violence has to be the work of people suffering some kind of mental disorder.

Second, we measured mentions of mental illness and violence, including schizophrenia, bipolar disorder, sociopathy, psychopath, depression, personality disorder, and psychosis. We coded the presence of additional, subjective facts, in news stories about mass shootings, mental health, and ethnicity. We reviewed each news story to determine if race of the shooter is associated with external loci of control like substance use, history of abuse or trauma, bullying, stressful life events, homelessness, gang infested living conditions, and dysfunctional family 
living. It is believed that examining the use of these words in news stories involving tragic crime might begin to help us understand or consider the role the media may plain in explaining the cause of violent acts and how exposure to those national stories might also encourage stereotypes and misunderstandings regarding the causes of mass violence.

Training took place over two weeks; each weekly session lasted one hour. During these sessions, the coders practiced on several news stories so that they and the investigator could identify and resolve problems with the coding scheme. Coders met to discuss reasoning behind their choices and then made the code book more precise based on this discussion. After the coding scheme was modified on the basis of these practice rounds, coding was then independent.

\subsection{Inter-Coder Reliability}

Inter-coder reliability was measured using percent agreement (also called simple agreement) (Landis \& Koch, 1977). Trial rounds of newspaper analysis were conducted in order to assure inter-coder reliability. The trial sample of data collection came from newspaper articles outside the random sample generated for this project. Through three trials of newspaper analysis, a 100\% agreement was reached on all variables except tone, which had a $90 \%$ agreement. For this study two trained coders, including the primary researcher, participated in coding training sessions. Once each coder was clear on what to look for when coding, each coder coded newspaper articles outside of the random sample produced for this study. The coders examined the news articles, and more precisely, the sentences and phrases in which the unit of analysis was found.

To analyze the content of news coverage, we developed a coding instrument. A random sample of ten news stories were independently coded by 4 coders to assess inter-coder reliability for each category. Reliability for each item was measured using Krippendorf alpha statistics, which all met conventional standards for adequate reliability of 0.69 or higher (Krippendorff, 2011). Using statistical analysis known as "bootstrapping," the coding categories in the current study produced coefficients that were $\alpha \geq 80$. According to Krippendorff (2004a, 2004b, 1989), alphas greater than .80 will provide researchers withhigh-quality data - producing results that are reliable and valid.

\subsection{Data Analysis}

Chi-square tests, as well as frequency tables, were analyzed to test the different research questions. The results section includes the quantitative data gained from conducting the tests. For each measure related to news media portrayals of the association among race, mental health and mass shootings, a $\chi^{2}$ test was used to compare the proportion of news stories mentioning race of the shooter, adjectives used to describe the shooter, and additional factors associated with race, mental illness and violence in news coverage. The $\chi^{2}$ test was used so that we could compare the proportion of news stories mentioning a given cause or 
attribute of the shooter in weeks after the Virginia Tech, Tucson, Aurora, and Newtown mass shootings. We specifically measured ethnicity to assess differences in news coverage with respect to the shooter's race in the mass shooting events. Specifically, we examined whether news media mentions of race and mental illness as a cause of the violent tragedy were assumed to be related.

\section{Results}

During the coding period, there were 170 articles obtained specifically focused on individual shooters. Frequencies and crosstabs were used to show how many stories were found about individual shooters and also used to make comparisons. Chi-square analyses were then used to show whether there was a significant difference in the race of the male shooter and the frequency of the descriptive language used in the story. All articles that featured individual shooters found and published on the landing page of the news websites dealing with the shooter and mass shooting were coded. Headings and headlines were also tallied for all sources. Articles were also printed from all websites that were found on the main homepage under top stories or headlines.

RQ1: Do differences in the types of facts used in a crime story exist among various racial groups? Thus, will newspapers report in different frequencies objective and subjective facts for shooters belong to different ethnic groups?

Coders found that subjective facts about shooters of color were observed at higher

As Table 1 shows, subjective facts are presented at a much higher frequency than objective facts for shooters/offenders of color. For example, offender and victim race are reported with higher frequencies than Caucasian shooters and offenders. One other subjective facts-mental health and other aggravating circumstances-were reported at higher frequencies. Given that subjective facts are less critical for understanding what happened, it is not surprising they receive more attention in the news, suggesting that newspapers do provide unnecessary "facts" of a story-facts which can perpetuate stereotypes.

RQ2: Does racial information/stereotypes about a crime involving a mass shooter increase when the shooter is a person of color? In other words, to what

Table 1. Frequencies of objective and subjective facts by ethnicity of the shooter in crime stories.

\begin{tabular}{cccc}
\hline Ethnicity of the Shooter & Objective Fact & Subjective Fact & Totals \\
\hline Caucasian & 69 & 7 & 76 \\
African-American & 10 & 44 & 54 \\
Hispanic & 2 & 19 & 21 \\
Asian & 0 & 2 & 2 \\
Native American & 0 & 0 & 0 \\
Muslim & 1 & 16 & 17 \\
Pacific Islander & 0 & 0 & 0 \\
Totals & 82 & 88 & 170 \\
\hline
\end{tabular}

Note: Numbers in table represent a single news story; $\mathrm{N}=170$ news stories. $\chi^{2}(6, \mathrm{~N}=170)=25.26, p<.001$. 
extent do crime news stories focus attention on uncharacteristic offenders and use words to frame the ethnicity of the shooter?

RQ3: How do portrayals of offenders' mental health vary in newspaper coverage?

According to Table 2, of the 171 news stories which shooter's race was identified analysis revealed that more often than not, crimes committed by shooters of color are portrayed in the news stories as irrational, unexplainable and senseless. This characterization of crime as random and inexplicable is common in most crime reporting (Surette, 1994, 1998) but we found it especially characteristic of crimes committed by minorities. However, when the shooter was coded as Caucasian, newspaper coverage often described the motive for the crime as one related to the mental health of the offender.

Not surprisingly, we found that in the majority of the stories where the shooter was Caucasian, the shooter was often presented as a "hero" and as a blameless individual (see Table 2). News reports of White shooters typically gave extensive descriptions of the motives of the shooter, implying that there was no other choice but to shoot.

Hero: We found that of the $\mathrm{N}=170$ stories, $75 \%$ of the stories involving a White shooter included the word or references to hero while shootings that involved lone shooters of color using the hero was found in $25 \%$ of the stories $(P<.001)$. Here we list examples of this category obtained in news headlines: 1$)$ "Filmmaker Outraged 'White' Cop Praised as Hero For Shooting Somali;" 2) "The hero cops who saved dozens of hostages," 3)" 'Hero' firefighter tackled elementary school gunman, officials say,." 4) "These Orlando shooting heroes prove people are fundamentally good," 5) "Army vet "hero' Chris Mintz opens up about Oregon college shooting," 6) "Slain Dallas Cop Might ve Been A White Supremacist. Still A Hero", and 7) "Kansas City shooting hero: Trump should address hate."

Table 2. Frequencies of Descriptive language found in news stories of mass shootings by race of the shooter.

\begin{tabular}{ccccccc}
\hline $\begin{array}{c}\text { Frequency of the Descriptive } \\
\text { Language of Shooter }\end{array}$ & White & Black & Asian & Hispanic & Muslim & Total \\
Hero & 24 & 5 & 0 & 3 & 0 & 32 \\
$\mathrm{X}^{2}=74.50$, df $4, p<.001$ & $(75 \%)$ & $(16 \%)$ & $(0 \%)$ & $(9 \%)$ & $(0 \%)$ & $(100 \%)$ \\
Terrorist & 6 & 12 & 2 & 2 & 13 & 35 \\
$\mathrm{X}^{2}=105.541$, df $4, p<.0000$ & $(17 \%)$ & $(34 \%)$ & $(6 \%)$ & $(6 \%)$ & $(37 \%)$ & $(100 \%)$ \\
Thug & 9 & 30 & 0 & 16 & 2 & 57 \\
$\mathrm{X}^{2}=78.71$, df $4, p<.0000$ & $(16 \%)$ & $(53 \%)$ & $(0 \%)$ & $(28 \%)$ & $(3 \%)$ & $(100 \%)$ \\
Mentally Ill & 37 & 7 & 0 & 0 & 2 & 46 \\
$\mathrm{X}^{2}=137.71$, df $4, p<.0000$ & $(80 \%)$ & $(16 \%)$ & $(0 \%)$ & $(0 \%)$ & $(4 \%)$ & $(100 \%)$ \\
Totals & 76 & 54 & 2 & 21 & 17 & 170 \\
& $(45 \%)$ & $(32 \%)$ & $(1 \%)$ & $(12 \%)$ & $(10 \%)$ &
\end{tabular}

Note: Numbers in the table represent frequency of the descriptor category. ${ }^{*}$ Percentages reflect proportion of stories obtained within the row. 
Terrorist/terrorism: According to data obtained, we found that $83 \%$ of the stories used the words to terrorist or terrorism when reporting mass shootings that involved shooters of color while only $17 \%$ of the stories where the shooter was Caucasian were found to use the words $(P<.0000)$. allegedly uses victims and targets for political and symbolic purposes (Lewis, 2005). Attacks are designed to create an atmosphere of fear or a sense of threat (Lewis, 2005). Examples of this term found in headlines are:

Examples of headlines coded in this category are: 1) "Why White Men Are "Gunmen" and Muslim Men Are "Terrorists," 2) "San Bernardino shooting: Isil claims attack as reports suggest wife came to US to perpetrate terror,"; 3): FBI now consider attack by Syed Farook and Tashfeen Malik "act of terrorism," 4) "49 killed in shooting at Florida nightclub in possible act of Islamic terror," 5) "ISIS claims responsibility for Florida gay club massacre: American-Afghan terrorist phoned 911 to pledge allegiance to group DURING attack before he was killed by cops," 6) "Yes, It Was A Muslim Terrorist Attack In Munich... Several Dead."

Thug/Criminal: In terms of the frequency by which news stories depicted Blacks as criminals, data found that news outlets regularly used mugshots to depict and highlight criminal histories $(P<.0000)$, reinforcing dangerous and racist stereotypes about Blacks.

Examples of headlines coded in this category were: 1) "Gone Away. Thugs Involved in Execution-Style Shooting in Downtown Park Sentence," 2) "Rap artists who are basically thugs" are the cause for Wednesday night's shooting, and 3) "The changing context of who gets called a 'thug' in America."

Mental Illness: Data collected in this study found that when compared to shooters of color, news stories frequently referred to Caucasian shooters as mentally ill $(\mathrm{P}<.0000)$. Examples of headlines coded in this category were: 1$)$ "Mental Illness Not an Explanation for Violence," 2) "The Role of Mental Illness in Shootings," 3) "Charleston: Why didn't anyone help Dylan Roof:; 4) "Mental Illness and Gun Violence," 5) "Data Suggest 'Gun Violence Epidemic' Is Actually a Mental Illness;" 6) "Paul Ryan blames mass shootings on mental health laws;" 7) "The Charleston Massacre: Mental Illness Common Thread for Mass Shooting," 8) "Gun Violence and Mass Shootings. Is Mental Illness to Blame?" and 9) "Post-mass shootings, little changes in Florida on mental illness and access to guns." Common news accounts of mental illness always seemed to involve a sensationalized and violent crime in which the victim is killed by a perpetrator suffering from some mental health illness (Fawcett, 2015).

With no clear patterns on the cultural background of mass shooters, it appears as if news media are giving increased attention to the mental health in order to explain "causes" of mass shootings. Analysis of the words used in national media seem to suggest that in the wake of multiple mass shootings media stories do not go beyond the issues of shooter's racial and/or mental health identification.

\section{Discussion}

In the context of the current dialogue around mental health and gun control 
following the Orlando Night Club shooting in June 2016, it is important to understand the public's exposure to news media messages about lone shooters and the descriptive language use to describe the shooters. When setting up the illusory correlation that White male shooters frequently suffer from mental illness yet shooters of color are described in terms of intrinsic attributions, it is possible that these word/shooter associations in media stories not only take away personal responsibility from shooters based on their race, but may also be responsible for perpetuating stereotypes concerning Black and Muslim men. The findings suggest that the notion that print news stories builds most stories about lone shooters center around certain frames that are serendipitously associated with minority groups, such as Caucasian shooters either as heroes or as individuals suffering from mental illness, and Blacks as thugs while Muslims are terrorists. We found that print news, at least in their headlines, employ a variety of these stereotypical frames and the deciding factor seems to be race of the shooter. Future research should consider how public exposure to acts of violence in the news media influences public perceptions of the causes for the violence. In fact, studies in this area could determine the effect that frequent exposure to these types of stories has on support for improving public mental health services.

The research reported here is an important extension of current literature on media representations of racial and ethnic groups in terms of mass tragedies (e.g., Chiricos \& Eschholz 2002; Dixon \& Linz, 2000a, 2000b; Klein \& Naccarato, 2003; Entman \& Rojecki, 2000). Importantly, this work yields two broad conclusions. First, and most generally, the analyses support the idea that U.S. media rely on different words and descriptive language when covering crimes involving African Americans or Muslims. For example, after the "Dylan Roof incident," media narrative formed quickly for him in that we read in news stories that Roof probably had some "mental issues and didn't know he had done anything wrong" (Wing, 2014). It seems as if media coverage humanized Roof and referred to him as a sick, victim of mistreatment or inadequate mental health resources.

Second, the findings suggest that frequent exposure to these stories of mass shootings and the use of descriptors based on race are being fed a media diet of stereotypes and misperceptions, that perhaps may downplay White shooters for their crimes while criminalizing shooters of color through language and images (Adams, 2015). While this may be a bold statement, researchers should further explore this hypothesis by determining the effect of exposure to the language on stereotypes held in terms of people of color. Perhaps an experiment by which language used in the story goes contrary to the stereotype already present in media. Data obtained might be able to show clearly the role that certain words and language have on our perceptions of shooters. In this line of research, the hypothesis under investigation is the idea that the use of language and descriptors may influence the extent to which racial minorities may or may not be perceived as thugs, terrorists, or criminals. Thus, the frequent reporting of Black shooters as thugs or criminals may be a case of media reflecting their own biases by por- 
traying Blacks as thugs.

\section{Limitations}

Online newspapers were the only form of media used for this study. Future research might include other forms of media such as radio, magazines, television, Facebook, Twitter, and print news sources. Relying on online newspapers limits the study because not all newspapers are accessible online. Even though it has its limitations, it is important to note that searching news archives online has proved to be a respectable tool to assist researchers.

This research topic can benefit from future research. Theoretically, future studies could focus on coupling framing with other theories like the elaboration likelihood model to help explain message processing and effects. For example, the extended elaboration likelihood model focuses on persuasive messages, and suggests that news stories on breaking crime can act as persuasive messages if they are read with intent, as opposed to being skimmed (see Solloway et al., 2013).

Future studies could look more deeply at the link between framing and effects of stereotyped labels found in news stories. Future research could also focus on emotions that elicited by words used in the headline and the impact altruistic and prosocial behavior have on young children. While seminal work on framing effects focused primarily on cognitive framing, a large portion of current framing research focuses on emotionality. That said, many of the emotions currently studied tend to be negatively valenced emotions, such as threat, anger, and fear.

Future research could also look into how the new media environment, including the Internet, social media, and new technology, is shifting how information is processed online, and the depth in which readers engage with online stories in the age of information overload. Papacharissi (2011) claims that new technologies "blend previously individuated mass media," which reinforces the idea that news is now being accessed via multiple channels, both print and online, and news is being conceptualized in broader terms (p. 17).

The present study uses a content analysis of a large number of major news stories that covered shootings in the last five years. Content analytic research was deemed appropriate for this study because it determines at an early stage how a group is represented in a medium and genre and provides a quantitative description of how those groups are represented (e.g., are Blacks or Whites more often portrayed as perpetrators or victims of crime).

What this exploratory research does imply is a need for further empirical research in this area. In fact, use of framing theory in media representations of race and ethnic groups in crime news should center on media use of thematic versus episodic frames. That is, in terms of shooters involved in mass tragedies, to what extent does the media rely on episodic or thematic frames to educate and inform consumers? Recall that an episodic frame focuses on an individual while a thematic frame focus on the issues. An episodic frame focuses on a single event; a thematic frame focuses on trends over time. 
Research in this area could be used to help test the hypotheses that episodic frames are more likely to keep focus on the individual while thematic frames focus on educating audiences on the conditions that led to the event. Thus, research incorporating framing theory would test the ideas (and aid journalists) in how to approach their audiences: episodic frames more likely approach the audience as consumers ("news you can use") in contrast to thematic frames, which approach the audience as citizens (Entman \& Gross, 2008). Programmatic research in this area gives mass media one solution to problems covering lone wolf shooters and mass tragedies. Data could provide valid evidence that episodic frames need to provide better information while thematic frames will ask for better policies.

\section{Conclusions}

Movies, television and the news are all guilty of publishing media content considered to encourage racist beliefs. Despite the progress that has been made in our culture, it is apparent that media still print news stories that use adjectives that are associated with people of color. News media serve as a powerful mode of communication and have incredible power in influencing public opinion on controversial topics, especially those topics that involve race, gun violence, shootings, killings, and injuring innocent victims.

If change is to come about, media outlets need to start facilitating conversations about race and crime in the $21^{\text {st }}$ century. Perhaps journalists should face their own personal biases and/or understand that words have meaning before using racist language in their headlines. Or perhaps we in the journalism and strategic communication industry need to start dialogue that educates consumers how the NRA, with 5 million predominantly white male members and \$205 million in annual revenue may also play into the white shooter hero/mentally ill stereotypes. Research tells us that $47 \%$ males and 33 percent of whites in America own guns, while only 18 percent of non-White Americans actually possess guns or firearms. In fact, few blacks are members of the NRA nor has the NRA any attempt to increase the number of black people in the organization.

In the meantime, it is hoped that this study incites scholars and professionals to write profiles of shooters in objective ways and to refrain from words like "lone wolf," "thug" or "terrorist." Perhaps the data obtained in this study encourage honest dialogue and conversations about violence in America.

\section{References}

Adams, J. (2015). Why White Mass Murderers Aren't Called The T-Word. http://www.huffingtonpost.com/joshua-adams/why-white-mass-murderers-_b_761741 $\underline{2 . h t m l}$

Appelbaum, P. S., \& Swanson, J. W. (2010). Gun Laws And mental Illness: How Sensible Are the Current Restrictions? Psychiatric Services, 61, 652-654. https://doi.org/10.1176/ps.2010.61.7.652

Barlow, M. H. (1998). Race and the Problem of Crime in Time and Newsweek Cover Stories, 1946-1995. Social Justice, 25, 149-182. 
Barlow, M. H., Barlow, D. E., \& Chiricos, T. G. (1990). Economic Conditions and Ideologies of Crime in the Media: A Content Analysis of Crime News. Crime and Delinquency, 41, 3-19. https://doi.org/10.1177/0011128795041001001

Butler, A. (2015). Shooters of Color Are Called "Terrorists" and "Thugs." Why Are White Shooters Called "Mentally Ill"?

https://www.washingtonpost.com/posteverything/wp/2015/06/18/call-the-charleston-c hurch-shooting-what-it-is-terrorism/?utm_term $=.937 \mathrm{bcdfb} 4 \mathrm{e} 84$

Dixon, T. L., \& Linz, D. (2000a). Race and the Misrepresentation of Victimization on Local Television News. Communication Research, 27, 547-573. https://doi.org/10.1177/009365000027005001

Dixon, T. L., \& Linz, D. (2000b). Overrepresentation and Underrepresentation of African Americans and Latinos as Lawbreakers on Television News. Journal of Communication, 50, 131-154. https://doi.org/10.1111/j.1460-2466.2000.tb02845.x

Dixon, T. L., Azocar, C. L., \& Casas, M. (2003). The Portrayal of Race and Crime on Television Network News. Journal of Broadcasting \& Electronic Media, 47, 498-523. https://doi.org/10.1207/s15506878jobem4704_2

Entman, R. M. (1990). Modern Racism and the Images of Blacks in Local Television News. Critical Studies in Mass Communication, 7, 332-345. https://doi.org/10.1080/15295039009360183

Entman, R. M. (1992). Blacks in the News: Television, Modern Racism, and Cultural Change. Journalism Quarterly, 69, 341-361. https://doi.org/10.1177/107769909206900209

Entman, R. M. (1993). Framing: Toward Clarification of a Fractured Paradigm. Journal of Communication, 43, 51-58. https://doi.org/10.1111/j.1460-2466.1993.tb01304.x

Entman, R. M. (1994a). African Americans According to TV News. Media Studies Journal, 8, 29-38.

Entman, R. M. (1994b). Representation and Reality in the Portrayal of Blacks on Network Television News. Journalism \& Mass Communication Quarterly, 71, 509-520. https://doi.org/10.1177/107769909407100303

Entman, R. M., \& Gross, K. A. (2008). Race to Judgement: Stereotyping Media and Criminal Defendants. Law and Contemporary Problems, 71, 94-133.

Entman, R. M., \& Rojecki, A. (2000). The Black Image in the White Mind: Media and Race in America. Chicago, IL: University of Chicago Press.

Fawcett, K. (2015). How Mental Illness Is Misrepresented in the Media: Insidious Portrayals on TV Shape Perceptions about Real-Life People with Psychological Disorders. U. S. News \& World Report, 16 April 2015.

http://health.usnews.com/health-news/health-wellness/articles/2015/04/16/how-mental -illness-is-misrepresented-in-the-media

Gilliam, F. D., \& Iyengar, S. (2000). Prime Suspects: The Influence of Local Television News on the Viewing Public. American Journal of Political Science, 44, 560-573. https://doi.org/10.2307/2669264

Grabe, M. E. (1999). Television News Magazines and Functionalism. Critical Studies in Mass Communication, 16, 155-171. https://doi.org/10.1080/15295039909367084

Howard, T. C., Flennaugh, T. K., \& Terry, C. L. (2012). Black Males, Social Imagery, and the Disruption of Pathological Identities: Implications for Research and Teaching. Educational Foundations, 26, 85-102.

Klein, R. D., \& Naccarato, S. (2003). Broadcast News Portrayal of Minorities: Accuracy in Reporting. American Behavioral Scientist, 46, 1611-1616.

https://doi.org/10.1177/0002764203254617 
Krippendorff, K. (1989). Content Analysis. In E. Barnouw, G. Gerbner, W. Schramm, T. L. Worth, \& L. Gross (Eds.), International Encyclopedia of Communication (Vol. 1, pp. 403-407). New York: Oxford University Press.

http://repository.upenn.edu/asc_papers/226

Krippendorff, K. (2004a). Content Analysis: An Introduction to Its Methodology. Thousand Oaks, CA: Sage.

Krippendorff, K. (2004b). Reliability in Content Analysis: Some Common Misconceptions and Recommendations. Human Communication Research, 30, 411-433. https://doi.org/10.1111/j.1468-2958.2004.tb00738.x

Krippendorff, K. (2011). Computing Krippendorff's Alpha-Reliability. Philadelphia, PA: Annenberg School for Communication Departmental Papers.

Landis, R. J., \& Koch, G. (1977). The Measurement of Observer Agreement for Categorical Data. Biometrics, 33, 159-174. https://doi.org/10.2307/2529310

Lewis, J. (2005). Language Wars: The Role of Media and Culture in Global Terror and Political Violence. London: Pluto Press.

Lewis, S. C., \& Reese, S. D. (2009). What Is War on Terror? Framing through the Eyes of Journalists. Journalism \& Mass Communication Quarterly, 86, 85-102. https://doi.org/10.1177/107769900908600106

McCauley, C., Moskalenko, S., \& Van Son, B. (2013). Characteristics of Lone-Wolf Violent Offenders: A Comparison of Assassins and School Attackers. Home, 7. http://www.terrorismanalysts.com/pt/index.php/pot/article/view/240

McGinty, E. E, Webster, D. W., Jarlenski, M., \& Barry, C. L. (2014). News Media Framing of Serious Mental Illness and Gun Violence in the United States, 1997-2012. American Journal of Public Health, 104, 406-413. https://doi.org/10.2105/AJPH.2013.301557

Milner, A. N., George, B. J., \& Allison, D. B. (2016). Black and Hispanic Men Perceived to Be Large Are at Increased Risk for Police Frisk, Search, and Force. PLoS ONE, 11, e0147158. https://doi.org/10.1371/journal.pone.0147158

Pritchard, D., \& Hughes, K. D. (1997). Patterns of Deviance in Crime News. Journal of Communication, 47, 49-67. https://doi.org/10.1111/j.1460-2466.1997.tb02716.x

Reiner, R., Livingstone, S., \& Allen, J. (2003). From Law and Order to Lynch Mobs: Crime News Since the Second World War. In P. Mason (Ed.), Criminal Visions: Media Representations of Crime and Justice (pp. 13-32). Portland: Willan Publishing.

Russell, K. K. (1998). The Color of Crime: Racial Hoaxes, White Fear, Black Protectionism, Police Harassment and Other Macroaggressions. New York: New York University Press.

Sacco, V. F. (1995). Media Constructions of Crime. Annals of the American Academy of the Political and Social Sciences, 539, 141-154. https://doi.org/10.1177/0002716295539001011

Saleem, M., Prot, S., Anderson, C. A., \& Lemieux, A. F. (2015). Exposure to Muslims in Media and Support for Public Policies Harming Muslims. Communication Research, 3.

Singletary, M. W., \& Lipsky, R. (1977). Accuracy in Local TV News. Journalism Quarterly, 54, 362-368. https://doi.org/10.1177/107769907705400220

Smile, C., \& Fakunle, D. (2016). From “Brute” to "Thug:” The Demonization and Criminalization of Unarmed Black Male Victims in America. Journal of Human Behavior in the Social Environment, 26, 350-366. https://doi.org/10.1080/10911359.2015.1129256

Statista (2017).

https://www.statista.com/statistics/476456/mass-shootings-in-the-us-by-shooter-s-race I 
Strate, L. (1985). Heroes, Fame and the Media. Et Cetera: A Review of General Semantics, 42, 47-53.

Surette, R. (1994). Predator Criminals as Media Icons. In G. Barak (Ed.), Media, Process, and the Social Construction of Crime (pp. 131-158). New York: Garland Publishing.

Surette, R. (1998). Media, Crime, and Criminal Justice. Belmont, CA: Wadsworth. Washington Post, "Md. Student Is Accused of Bat Attack on Teacher." Oct. 21, 2005. Washington Post, "Teenager is Arrested in Slaying of Lawyer's Wife." Oct. 21, 2005. Washington Post, “Baby Injured.” Oct. 29, 2005.

Weiss, A., \& Chermak, S. M. (1998). The News Value of African American Victims: An Examination of the Media's Presentation of Homicide. Journal of Crime and Justice, 21, 71-88. https://doi.org/10.1080/0735648X.1998.9721601

Wing, N. (2014). When The Media Treats White Suspects and Killers Better than Black Victims.

http://www.huffingtonpost.com/2014/08/14/media-black-victims_n_5673291.html

Submit or recommend next manuscript to SCIRP and we will provide best service for you:

Accepting pre-submission inquiries through Email, Facebook, LinkedIn, Twitter, etc. A wide selection of journals (inclusive of 9 subjects, more than 200 journals)

Providing 24-hour high-quality service

User-friendly online submission system

Fair and swift peer-review system

Efficient typesetting and proofreading procedure

Display of the result of downloads and visits, as well as the number of cited articles

Maximum dissemination of your research work

Submit your manuscript at: http://papersubmission.scirp.org/

Or contact ajc@scirp.org 